\title{
Complex interactions between temperature and relative humidity on water balance of adult tsetse (Glossinidae, Diptera): implications for climate change
}

\author{
Elsje Kleynhans and John S. Terblanche* \\ Department of Conservation Ecology and Entomology, Stellenbosch University, Stellenbosch, Republic of South Africa
}

\section{Edited by:}

Catherine Loudon, University of California at Irvine, USA

\section{Reviewed by:}

Laura Ann Miller, University of North Carolina at Chapel Hill, USA

Eran Gefen, University of

Haifa - Oranim, Israel

*Correspondence:

John S. Terblanche, Department of Conservation Ecology and

Entomology, Stellenbosch University,

Private Bag X1, Matieland 7620,

Republic of South Africa.

e-mail: jst@sun.ac.za
Insect water balance plays an important role in determining energy budgets, activity patterns, survival, and population dynamics and, hence, geographic distribution. Tsetse (Glossina spp.) are important vectors of human and animal disease occupying a wide range of habitats in Africa and are notable for their desiccation resistance in xeric environments. Here, we measure water balance and related traits [water loss rate (WLR), body water content (BWC), body lipid content $(B L C)$ and body mass] in adult flies across a range of temperature $\left(20-30^{\circ} \mathrm{C}\right)$ and relative humidity $(0-99 \%)$ combinations in four tsetse species from both xeric and mesic habitats. WLRs were significantly affected by measurement under different temperature and relative humidity combinations, while BWC, BLC, and body mass were less affected. These results provide support for mass-independent inter- and intra-specific variation in WLRs and survival times. Furthermore, water balance responses to variation in temperature and relative humidity are complex in Glossina, and this response varies within and among species, subgroups, and ecotypes in terms of both magnitude of effects and the direction of change. Different effects of temperature and relative humidity within and among experimental conditions and species suggests cuticular permeability and saturation deficit are likely to be key factors in forecasting tsetse water balance responses to climate variability. This complicates potential forecasting of tsetse distribution in the face of climate change.

Keywords: water balance, Glossinidae, trypanosomiasis, adaptive variation, desiccation resistance, ecotype

\section{INTRODUCTION}

Water balance plays a critical role in determining insect fitness, geographic range, and, in the case of disease vectors, disease dynamics in the face of climate change (Danks, 2000; Chown and Nicolson, 2004; Chown et al., 2011). Climate change is typically interpreted in terms of variation in mean ambient temperature. However, it is increasingly apparent that regional variation in temperature and humidity are likely to be significant in understanding the impacts on insect populations (Easterling et al., 2000; Tebaldi and Sansó, 2009; Benoit and Denlinger, 2010). Terrestrial insects face considerable challenges in balancing water gained and lost largely due to their high surface area to volume ratio (Hadley, 1994).

Four main physiological mechanisms provide resistance or tolerance to dehydration in xeric (dry) environments. First, cuticular hydrocarbons form a barrier of hydrophobic bonds that increase desiccation resistance (Edney, 1977; Jurenka et al., 2007; Bazinet et al., 2010). Insects can thus exploit this low cuticular permeability by reducing metabolic rate (e.g., through quiescence, alteration of gas exchange patterns or water conservation in the sub-elytral chamber; e.g., Terblanche et al., 2010; reviewed in Chown et al., 2011; but see also discussion in Woods and Smith, 2010). This is further maximized by behavioral avoidance of desiccating conditions, such as limiting activity to a time of day when desiccation is least likely (e.g., Kessler and Guerin, 2008). However, for each species an environment-specific transition temperature may exist beyond which cuticular lipids melt, resulting in rapidly increased cuticular permeability and, ultimately, accelerated water loss (Benoit, 2010; Gibbs, 2011). Second, insects increase the quantity of water available in their bodies to resist dehydration by (i) ingestion of free standing water or nectar, (ii) absorbing water from the ambient environment, (iii) the conversion of metabolic water, or (iv) increasing body size over evolutionary time-scales (reviewed in Hadley, 1994; Benoit and Denlinger, 2010; Chown et al., 2011; Yoder et al., 2011). Higher carbohydrate content can increase bound water reserves and has been associated with desiccation resistance in some insects (see, e.g., Gibbs et al., 1997; Marron et al., 2003). The complementary provision of water through metabolism may include altering metabolic fuels, e.g., from lipids to carbohydrates, to yield higher metabolic water or decreased mass-specific metabolic rate to limit respiratory water loss (e.g., Marron et al., 2003; Terblanche et al., 2010, but see discussions in Woods and Smith, 2010). Third, insects enhance desiccation tolerance by production of cellular compounds which maintain cell function under dehydration stress (e.g., heat shock proteins, Lopez-Martinez et al., 2009; Benoit and Denlinger, 2010). Finally, rapid, intra-individual phenotypic adjustments are a wide-spread physiological mechanism 
employed to enhance desiccation tolerance or resistance under dehydrating conditions (e.g., Woods and Harrison, 2001; Hoffmann et al., 2003; Terblanche and Kleynhans, 2009; Bazinet et al., 2010; Terblanche et al., 2010; reviewed in, e.g., Chown et al., 2011).

Generally, insects from xeric environments are either more desiccation resistant or desiccation tolerant than insects from mesic (moist) environments (Edney, 1967; Hadley, 1994; Le Lagadec et al., 1998; Gibbs and Matzkin, 2001; Hoffmann et al., 2003; Matzkin et al., 2009). However, insects from stable mesic environments might experience lower dehydration stress, resulting in an increased water loss rate (WLR) when exposed to xeric conditions (e.g., Yoder et al., 2011). Water balance traits can drive evolutionary processes, especially in insects associated with xeric environments, resulting in physiological diversification among individuals, populations, or species (Gibbs et al., 1997; Hoffmann and Harshman, 1999; Woods and Harrison, 2001; Chown and Terblanche, 2007; Gefen and Gibbs, 2009; Kleynhans and Terblanche, 2009; Matzkin et al., 2009; Simard et al., 2009; Benoit and Denlinger, 2010). Water balance trait variation can also extend to larger geographic scales (e.g., continental or global; Addo-Bediako et al., 2001; Chown, 2002; Hoffmann et al., 2003; Marron et al., 2003; Kleynhans and Terblanche, 2009).

Tsetse (genus Glossina) consists of 22 species which occupy a wide range of habitats in sub-Saharan Africa. Given their critical importance as a major vector of tropical human and animal disease (trypanosomiases), understanding the physiological drivers of tsetse water balance is crucial for predicting disease dynamics under climate change scenarios. Tsetse are classified into three major subgroups on the basis of morphological differences in the structure of the male genitalia (Rogers and Randolph, 1986; Leak, 1999). The three subgroups can also be differentiated by variation in physiology, behavior, and ecological characteristics related to sensitivity to moisture availability (Bursell, 1960). Tsetse population dynamics is affected by temperature and relative humidity variation in the field (Hargrove, 2004; Rogers and Robinson, 2004; Terblanche et al., 2008). Marked variation in daily and seasonal temperature and relative humidity has been measured in tsetseoccupied habitats (e.g., Hargrove, 2001, 2004; Jurenka et al., 2007). Tsetse can experience mean temperatures between 20 and $30^{\circ} \mathrm{C}$ within a single species' geographic range (e.g., Terblanche et al., 2006), with $1.2-5.6^{\circ} \mathrm{C}$ variation occurring seasonally (Jurenka et al. 2007) and varying by up to $20^{\circ} \mathrm{C}$ daily within a single location (Terblanche et al., 2008). Saturation deficits between 1 and $36 \mathrm{mB}$ have been observed (e.g., Figure 7.3 in Hargrove, 2004) while relative humidity can also vary substantially at either low or high mean temperatures (Jurenka et al., 2007). Thus, a wide range of saturation deficits can be experienced over the average flies' lifetime, across a species' geographic range, or among species. Early studies concluded that adult water balance was not an important factor in the occupancy of xeric environments (Bursell, 1959), although water balance physiology is clearly important to the pupal stage (Bursell, 1958; Kleynhans and Terblanche, 2009). This former view contrasts strongly with much of the modern water balance literature (e.g., Terblanche et al., 2006; reviewed in Chown et al., 2011) and we suggest that this conclusion may have been reached prematurely without due consideration of plastic physiological responses and the range of potential conditions which affect WLRs (see also Terblanche and Kleynhans, 2009). Moreover, it is likely that the entire Glossina genus could be adapted to xeric environments thereby masking inter-specific variation measured under a single set of conditions. Indeed, much of the early comparative work on tsetse water balance physiology focused on inter-specific comparisons made from measurements undertaken under a single or a few controlled relative humidity conditions at a single temperature (e.g., Bursell, 1959). Adult tsetse feed solely on blood which leads to them facing a set of unique challenges in suppressing dehydration in the off-host environment and maintaining a positive water balance while actively seeking a blood meal, mates, or producing offspring (see discussions in Benoit and Denlinger, 2010).

Here we measure aspects of water balance physiology in adults of four ecologically diverse species of tsetse under a range of environmentally-relevant combinations of temperature and relative humidity. We aim to answer three main questions regarding water balance physiology of tsetse. (1) How does a species, water balance physiology respond to changes in temperature and relative humidity? (2) Does the interaction between temperature and relative humidity elicit a consistent physiological response among individuals and among species in terms of magnitude and direction of change? This can be rephrased to ask if water balance responses to temperature and relative humidity are similar between species or ecotypes. (3) What conclusions can be drawn regarding the interplay of temperature and relative humidity on intra-specific survival times? If species, or ecotypes respond similarly for a given trait, then this would allow predicted climate change impacts to be generalized across tsetse species, or one could use data from a single species to forecast environmental effects across species. However, in combination, temperature and relative humidity may behave synergistically, eliciting complex physiological responses (Gibbs et al., 1997; Gibbs and Matzkin, 2001; Chown et al., 2011). If, on the other hand, tsetse species differ in their water balance physiology and responses to varying moisture and temperature, then forecasting climate change responses for the entire range of species will be considerably more complex.

\section{MATERIALS AND METHODS STUDY ORGANISMS}

We measured traits of water balance physiology in adults of Glossina brevipalpis Newstead (mesic), G. morsitans centralis Westwood (xeric), G. pallidipes Austen (xeric), and G. palpalis gambiensis Vanderplank (mesic; Diptera, Glossinidae). Pupae were received from a laboratory colony maintained at the Entomology Unit, FAO/IAEA Agriculture and Biotechnology Laboratory, Seibersdorf, International Atomic Energy Agency, Vienna, Austria, or from a laboratory colony maintained at the Onderstepoort Veterinary Institute, Pretoria, South Africa ( G. brevipalpis). The pupae (22-25 days old) were received via air cargo in well insulated nonairtight containers kept under controlled temperature conditions during transportation (typically $<2$ days of transport, temperature range $18-24^{\circ} \mathrm{C}$ controlled by two phase changing agents). Species were chosen to represent the three main tsetse subgroups: fusca (G. brevipalpis), palpalis (G. p. gambiensis), and morsitans (G. $m$. centralis and G. pallidipes). The fusca group resides in forests (mesic) and is the most ancestral of the three groups. The 
palpalis group is also associated with mesic habitats and the morsitans group with xeric savannahs. Here, ecotypes were assigned according to Kleynhans and Terblanche (2009).

Upon arrival, puparia were kept in a dark climate chamber (Labcon, South Africa) at $25^{\circ} \mathrm{C}$ and $76 \%$ relative humidity until emergence. Once the flies emerged, they were transferred into mesh cages and fed three times, every second day, using defibrinated, infection free bovine blood on a membrane-tray system (similar to methods described previously in Terblanche et al., 2004, 2005). After the third blood meal, adults were kept under controlled conditions (optimal, standard rearing conditions: $25^{\circ} \mathrm{C}$, $76 \%$ relative humidity) for a further $24 \mathrm{~h}$ before experiments begun. Water lost by excretion was negligible (see Bursell, 1960). Each treatment group $(n=30)$ emerged on the same day to standardize age across treatments. Treatments were conducted in random order.

\section{EXPERIMENTAL TREATMENTS}

Water balance traits were determined at three temperatures: $21 \pm 1.0,25 \pm 1.0$, or $29 \pm 1.0^{\circ} \mathrm{C}$; and three relative humidities: $<5$ (0\%), 73-77 (76\%), or $>95$ (99\%). Treatments and corresponding saturation deficits include the following temperature $\left(\right.$ in $\left.{ }^{\circ} \mathrm{C}\right)$, relative humidity (in \%) combinations: 21,99 (CW); 25,99 (IW); 29,99 (HW); 21,76 (CI); 25,76 (II); 29,76 (HI); 21,0 (CD); 25,0 (ID); and 29,0 (HD) where $\mathrm{C}=$ cold, $\mathrm{W}=$ wet, $\mathrm{I}=$ intermediate, $\mathrm{H}=$ hot, and $\mathrm{D}=$ dry. Saturation deficit is an index of the evaporative capability of the air calculated as:

$\mathrm{SD}=\mathrm{SVP}-\mathrm{AVP}$

where SD is the saturation deficit (in $\mathrm{mB}$ ), SVP is the saturation vapor pressure (in $\mathrm{mB}$ ) and AVP is the actual vapor pressure (in $\mathrm{mB}$ ). The SVP is a function of temperature (in ${ }^{\circ} \mathrm{C}$ ) and the actual vapor pressure is a function of relative humidity (in $\%)$. Temperature and relative humidity were recorded during all experiments using Thermocron iButtons (DS1402D-DR8, Dallas Semiconductors; $\pm 0.5^{\circ} \mathrm{C}$ and $1 \%$ accuracy at a 10 -min sampling rate).

Individual adult flies were placed separately into numbered $50 \mathrm{ml}$ pill vials with ventilation holes to achieve complete desiccation. Pill vials were randomly placed within airtight plastic $500 \mathrm{ml}$ desiccation jars. A $100-\mathrm{ml}$ vial inside the jar contained silica gel $(0 \%)$, saturated sodium chloride $(\mathrm{NaCl}, 76 \%)$, or Millipore filtered, doubly distilled water $(99 \%)$ to control relative humidity (see methods in Terblanche and Kleynhans, 2009). Care was taken to ensure that all treatment groups were handled for the same duration during transfer from the climate chamber to the vials and spent a similar amount of time outside the desiccating conditions during weighing ( 20-30 min per group). Gender ratios were not strictly controlled but accounting for size in statistical analyses typically eliminates sex effects on water balance physiology (see, e.g., Terblanche et al., 2006).

\section{PHYSIOLOGICAL WATER BALANCE TRAITS}

Treatments were performed for $24 \mathrm{~h}$ in the dark to suppress activity which can affect WLR. Bursell (1957a) concluded that relative humidity and hunger state affected tsetse activity. However, Terblanche et al. (2006) suggest that differences in activity levels do not account for WLR variation among populations or temperature treatments. Activity might affect the measured WLR estimates in response to stressful conditions (see Gibbs et al., 2003) or acclimation (see Hadley, 1994; Terblanche et al., 2006). However, during experimental treatments the adult flies did not show any significant differences in observed activity levels between treatments or species (and see Terblanche et al., 2006). We calculated WLR, body water content (BWC), and body lipid content (BLC) gravimetrically. Weighing took place for each fly individually on an electronic microbalance to $0.1 \mathrm{mg}$ (Mettler Toledo AX504). Body mass was recorded at the start of the experiment $\left(\mathrm{Mb}_{\mathrm{i}}\right)$ and after exposure to various controlled temperature and relative humidity treatments $\left(\mathrm{Mb}_{\mathrm{a}}\right)$. WLR was calculated by subtracting $\mathrm{Mb}_{\mathrm{a}}$ from $\mathrm{Mb}_{\mathrm{i}}$ and dividing the difference by the treatment time (in $\mathrm{h}$ ). Tsetse were dried to a constant mass at $50-60^{\circ} \mathrm{C}$ for approximately $72 \mathrm{~h}$ and re-weighed to determine dry mass (DM). The BWC was calculated as the difference between $\mathrm{Mb}_{\mathrm{i}}$ and $\mathrm{DM}$. Finally, body lipids were extracted using three chloroform:methanol (1:1 ratio) washes, once per day, baking dry at $50-60^{\circ} \mathrm{C}$ for approximately $72 \mathrm{~h}$ after the final wash and subsequent weighing. BLC was the difference between the mass after lipid extraction and DM.

\section{SURVIVAL TIME ESTIMATION}

Survival time was estimated given that the conversion rate of lipids to metabolic water is 1.08 and the critical lipid content is $4.2 \%$ of DM (Bursell, 1959). Furthermore, survival time is a function of all available water reserves and the rate at which water is lost, calculated as:

$S=\frac{((1.08 \times(\mathrm{BLC}-(0.042 \times \mathrm{DM}))+(\mathrm{BWC}-\partial))}{\mathrm{WLR}}$

where $S$ is survival time (in h), BLC is body lipid content (in $\mathrm{mg}$ ), $\mathrm{DM}$ is dry mass, BWC is the body water content (in $\mathrm{mg}$ ), $\partial$ is a constant critical BWC, and WLR is water loss rate (in $\mathrm{mg} / \mathrm{h}$ ). The critical BWC is given by Bursell (1959) as $0.0657 \mathrm{mg}$ for G. brevipalpis, $0.0645 \mathrm{mg}$ for G. m. centralis, $0.0661 \mathrm{mg}$ for G. pallidipes, and $0.0656 \mathrm{mg}$ for G. p. gambiensis. To our knowledge, tsetse have an exclusively proline-driven metabolism and their capacity for carbohydrate metabolism is limited (Norden and Paterson, 1969; Bursell et al., 1974; Bursell, 1977). Therefore, it is unlikely that tsetse rely on carbohydrate-bound water to increase BWC, and it is also unlikely that changes in metabolic pathways (e.g., from carbohydrates to lipids) are used to increase net water content and thereby increase survival times. Consequently, these latter factors were omitted from the estimation of survival time.

\section{STATISTICAL ANALYSIS}

The response of WLR, BWC, and BLC in response to variation in temperature, relative humidity or the interaction of temperature and relative humidity was analyzed using type 3 generalized linear models (GLZ; ProcGenmod; SAS Enterprise Guide version 4.1, SAS Institute, Inc., Cary, NC, USA) with a normal distribution of errors and an identity link function. Survival time was analyzed in a similar manner to investigate the survival time in response to variation in species, temperature, and relative humidity. In all GLZ analyses, deviance was scaled to 1 to correct for overdispersion. The four tsetse species exhibit substantial intra-specific size variation. 
To control for potential size variation among treatment groups, $\mathrm{Mb}_{\mathrm{i}}$ of each tsetse was incorporated as a covariate as a standard measure of individual size. We used STATISTICA (v. 10, Statsoft, Tulsa, USA) to calculate the size adjusted or least-square mean results for graphs. Overlap in 95\% CLs was used to test for statistically significant homogeneity among treatment groups or species.

\section{RESULTS}

\section{WATER LOSS RATE}

In all four species examined, WLRs were significantly affected by body mass of individuals, test temperature, and relative humidity (Table 1; Figure 1A). Glossina brevipalpis (mesic), G. m. centralis (xeric), and G. p. gambiensis (mesic) also showed significant interaction effects between temperature and relative humidity, although this was not the case for G. pallidipes (xeric). After adjustment for the mean mass across all four species (mean $\mathrm{Mb}_{\mathrm{i}}=33.99 \mathrm{mg}$ ), G. brevipalpis lost significantly more water at $29^{\circ} \mathrm{C}, 0$ and $76 \%$ relative humidities relative to all other species measured at these conditions. G. brevipalpis lost water significantly slower under moist conditions (i.e., at saturation deficits lower than $30.22 \mathrm{mB}$ ) than the other species (Figure 2).

All species lost water slower than expected at low saturation deficits and higher than expected at higher saturation deficits (Figures 3A-D). Generally, WLR for G. m. centralis were lower at lower saturation deficits (Figure 3B). Furthermore, G. brevipalpis showed a general positive association between WLR and temperature and a negative association between WLR and relative humidity. WLR increased significantly with higher temperature at $0 \%$ relative humidity and decreased significantly with increased relative humidity at 25 and $29^{\circ} \mathrm{C}$. In G. m. centralis at $25^{\circ} \mathrm{C}$ and $0 \%$ relative humidity, WLR was significantly higher relative to the other treatments. G. pallidipes showed the same general pattern, losing significantly more water at $25^{\circ} \mathrm{C}$ than at other temperatures, irrespective of relative humidity. For this species, WLR was significantly higher at $0 \%$ relative humidity than at ather values, irrespective of temperature. G. p. gambiensis lost water significantly faster at $29^{\circ} \mathrm{C}, 0 \%$ relative humidity compared to all other treatments. In summary, within-species variation in WLR is significantly influenced by temperature and relative humidity in $G$. brevipalpis (fusca group, mesic ecotype). At an intermediate temperature $\left(25^{\circ} \mathrm{C}\right), G$. m. centralis (morsitans group, xeric ecotype) WLR increases with decreased relative humidity. WLR is significantly higher at $0 \%$ relative humidity in G. pallidipes (morsitans group, xeric ecotype) and higher temperatures $\left(29^{\circ} \mathrm{C}\right)$ at $0 \%$, and $76 \%$ relative humidity treatments results in a significant increase in WLR of G. p. gambiensis (palpalis group, mesic ecotype).

Even after adjustment for body size within each species (i.e., among treatment groups), there was significant variation in WLR across treatments (Figures 1 and 2), even within ecotype groups. Specifically, WLR of xeric species differed significantly among five of the nine experimental treatments and mesic species differed significantly in all but three experimental treatments (Figure 2).

\section{BODY WATER CONTENT}

As expected, initial body mass generally did not vary among treatments within each species (Figure 1D). Mass-independent variation in BWC with temperature and relative humidity was significant for all species, although these effects were less pronounced than in the case of WLR (Table 1; Figure 1B). The main effect of relative humidity did not significantly affect BWC in G. m. centralis (Table 1). Generally, G. pallidipes had a lower BWC $(\sim 12.5 \%)$ relative to all other species across treatments (Figure 1B). G. brevipalpis had significantly lower BWC than G. p. gambiensis at $29^{\circ} \mathrm{C}$, 0 and $76 \%$ relative humidity.

\section{BODY LIPID CONTENT}

There was a significant interaction effect between temperature and relative humidity on BLC in G. brevipalpis and G. pallidipes, but no significant interaction effect in $G$. m. centralis or G. p. gambiensis. Only the main effect of temperature was significant for G. p. gambiensis (Table 1). In G. pallidipes, BLC was significantly lower at $29^{\circ} \mathrm{C}$ relative to $21^{\circ} \mathrm{C}$ across relative humidity treatments. By contrast, BLC was significantly higher in G. brevipalpis at $29^{\circ} \mathrm{C}$ than at 21 or $25^{\circ} \mathrm{C}$ across relative humidity treatments with the exception of $99 \%$ relative humidity where no significant differences in BLC were observed (Figure 1C).

\section{SURVIVAL TIME}

The estimated time to death by water and lipid exhaustion is a function of all three traits of water balance (WLR, BWC, and BLC) and provides a good indication of overall water balance, assuming negligible activity effects. Lower WLR, higher BWC, and higher BLC should all potentially result in increased survival time (see, e.g., discussion in Chown et al., 2011). Body mass had a significant influence on survival time (Table 2, covariate mean mass: $33.99 \mathrm{mg}$ ) and survival time varied among species and treatments when adjusted for differences in body size (Table 2). Moreover, the interaction effects of temperature and humidity also influenced survival time significantly (Table 2, Figure 4). However, since we were interested in the ecologically relevant variation in survival time among species, we also investigated survival time without adjusting for body mass (Figure 4). This suggested that the precise temperature and relative humidity combinations affected survival time of the different species and ecotype groups in a complex manner, and was not simply a consequence of body size variation. The slope of the relationship between temperature and survival time was generally negative. However, within-species slopes differed and were occasionally positive with increased temperature, for example, at $99 \%$ relative humidity in G. m. centralis. Glossina brevipalpis survived significantly longer than all other species at $21^{\circ} \mathrm{C}$ compared to the other temperature treatments at 0 and $76 \%$ relative humidity and at $99 \%$ relative humidity across all temperature treatments. G. p. gambiensis had significantly lower survival time relative to all species tested at $21^{\circ} \mathrm{C}$, $76 \% ; 29^{\circ} \mathrm{C}, 76 \%$, and all temperature treatments at $99 \%$ relative humidity.

Glossina brevipalpis (mesic) survived significantly longer than G. p. gambiensis (mesic) and G. m. centralis (xeric) survived significantly longer than G. pallidipes (xeric) at $29^{\circ} \mathrm{C}, 0 \%$ relative humidity. This suggests within-ecotype variation and higher resistance to desiccation through water balance traits in hot, dry environments in G. brevipalpis (mesic) and G. m. centralis 
Table 1 | Summary of generalized linear model results [degrees of freedom (d.f.), chi-square $\left(\chi^{2}\right)$ statistic, and corresponding $\boldsymbol{P}$-value $(\boldsymbol{P})$ ] for water loss rate (WLR in $\mathrm{mg} / \mathrm{h}$ ), body water content (BWC in $\mathrm{mg}$ ), and body lipid content (BLC in $\mathrm{mg}$ ) as dependent variables, initial body mass as a continuous predictor and relative humidity, temperature, or temperature and relative humidity interaction effect (indicated with $x$ ) as independent variables.

\begin{tabular}{|c|c|c|c|c|c|}
\hline Species & Trait & Parameter & d.f. & $x^{2}$ & $P$ \\
\hline \multirow[t]{9}{*}{ G. brevipalpis } & WLR & Body mass & 1 & 349.51 & $<0.0001$ \\
\hline & & Humidity & 2 & 165.44 & $<0.0001$ \\
\hline & & Humidity $\times$ temperature & 4 & 22.32 & 0.0002 \\
\hline & BWC & Body mass & 1 & 5857.33 & $<0.0001$ \\
\hline & & Humidity $\times$ temperature & 4 & 23.66 & $<0.0001$ \\
\hline & BLC & Body mass & 1 & 129.78 & $<0.0001$ \\
\hline & & Humidity & 2 & 38.37 & $<0.0001$ \\
\hline & & Temperature & 2 & 100.56 & $<0.0001$ \\
\hline & & Humidity $\times$ temperature & 4 & 55.55 & $<0.0001$ \\
\hline \multirow{8}{*}{ G. m. centralis } & BWC & Body mass & 1 & 5859.05 & $<0.0001$ \\
\hline & & Humidity & 2 & 2.07 & 0.3551 \\
\hline & & Temperature & 2 & 33.03 & $<0.0001$ \\
\hline & & Humidity $\times$ temperature & 4 & 17.53 & 0.0015 \\
\hline & BLC & Body mass & 1 & 75.62 & $<0.0001$ \\
\hline & & Humidity & 2 & 5.8 & 0.055 \\
\hline & & Temperature & 2 & 4.33 & 0.1146 \\
\hline & & Humidity $\times$ temperature & 4 & 8.36 & 0.0791 \\
\hline \multirow[t]{6}{*}{ G. pallidipes } & WLR & Body mass & 1 & 51.16 & $<0.0001$ \\
\hline & & Humidity & 2 & 127.17 & $<0.0001$ \\
\hline & & Temperature & 2 & 84.35 & $<0.0001$ \\
\hline & & Humidity & 2 & 13.7 & 0.0011 \\
\hline & & Temperature & 2 & 114.64 & $<0.0001$ \\
\hline & & Humidity $\times$ temperature & 4 & 74.53 & $<0.0001$ \\
\hline \multirow[t]{12}{*}{ G. palpalisgambiensis } & WLR & Body mass & 1 & 212.77 & $<0.0001$ \\
\hline & & Humidity & 2 & 90.43 & $<0.0001$ \\
\hline & & Temperature & 2 & 91.99 & $<0.0001$ \\
\hline & & Humidity $\times$ temperature & 4 & 205.29 & $<0.0001$ \\
\hline & BWC & Body mass & 1 & 13473.6 & $<0.0001$ \\
\hline & & Humidity & 2 & 41.64 & $<0.0001$ \\
\hline & & Temperature & 2 & 20.95 & $<0.0001$ \\
\hline & & Humidity $\times$ temperature & 4 & 123.26 & $<0.0001$ \\
\hline & BLC & Body mass & 1 & 38.01 & $<0.0001$ \\
\hline & & Humidity & 2 & 0.89 & 0.642 \\
\hline & & Temperature & 2 & 32.27 & $<0.0001$ \\
\hline & & Humidity $\times$ temperature & 4 & 7.54 & 0.1099 \\
\hline
\end{tabular}

Traits were measured for G. brevipalpis (mesic), G. morsitans centralis (xeric), G. pallidipes (xeric), and G. palpalis gambiensis (mesic). Non-significant effects are indicated in bold. 

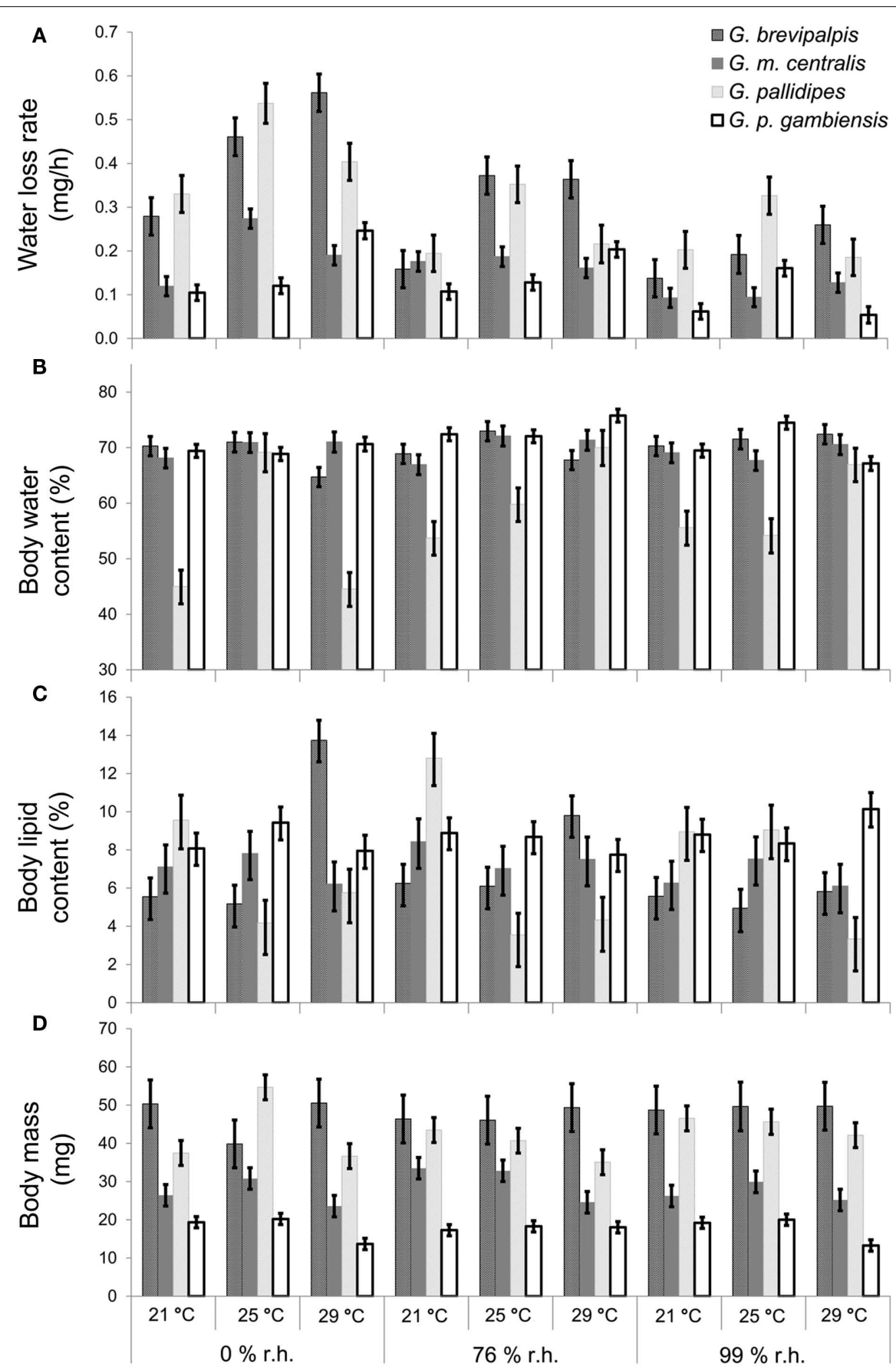

Treatment

FIGURE 1 | Mean ( $\pm 95 \%$ confidence intervals) results of Glossina brevipalpis (mesic), G. morsitans centralis (xeric), G. pallidipes (xeric), and G. palpalis gambiensis (mesic) (A) water loss rate (least-squares means in $\mathrm{mg} / \mathrm{h}$ ), covariate mean body mass $=33.99 \mathrm{mg}$, $(B)$ body water content (as a $\%$ of initial body mass), (C) body lipid content (as a $\%$ of initial body mass), and (D) initial body mass (in $\mathbf{m g}$ ). Water balance traits were measured at three different relative humidities and three different temperatures. (xeric). Furthermore, G. brevipalpis survived significantly longer than G. p. gambiensis, except at $25^{\circ} \mathrm{C}, 0 \%$ relative humidity, which suggests variation in desiccation resistance within the mesic ecotype.

\section{DISCUSSION}

Here, we measured water balance and related traits (WLR, BWC, and BLC) in adult flies across a range of temperature (20$\left.30^{\circ} \mathrm{C}\right)$ and relative humidity $(0-99 \%)$ combinations in four tsetse 

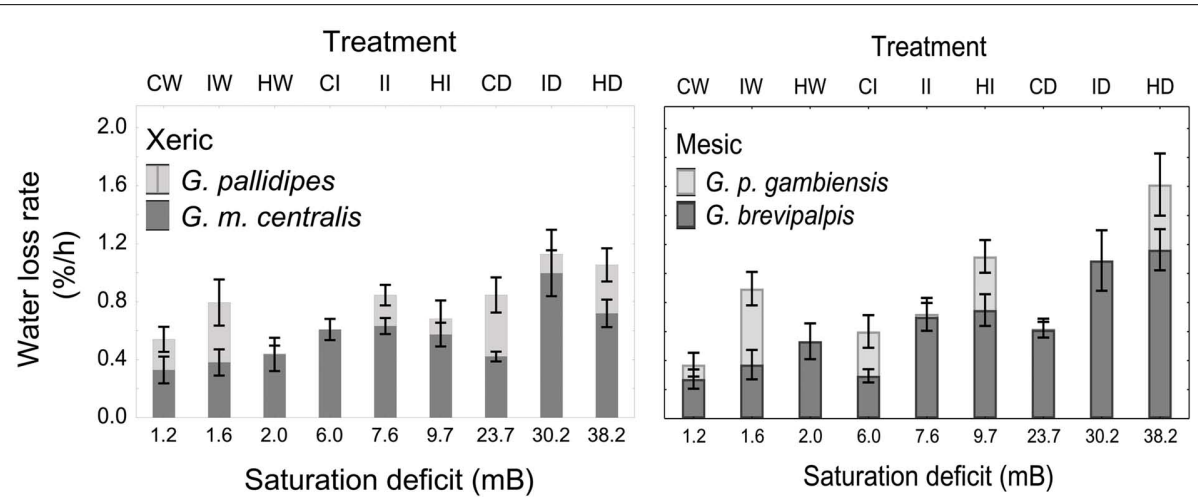

FIGURE 2 | Means ( $\pm 95 \%$ confidence intervals) water loss rates ( $\%$ of initial body mass lost per hour) across a range of saturation deficits corresponding to the respective temperature and relative humidity treatments for xeric (left) G. pallidipes and G. morsitans centralis and mesic (right) Glossina brevipalpis and
G. palpalis gambiensis. Treatments and corresponding saturation deficits (in $\mathrm{mB}$ ) include the following temperature (in ${ }^{\circ} \mathrm{C}$ ), relative humidity (in \%) combinations: 21,99 (CW); 25,99 (IW); 29,99 (HW); 21,76 (Cl); 25,76 (II); 29,76 (HI); 21,0 (CD); 25,0 (ID); and 29,0 (HD) where C, cold; W, wet; I, intermediate; $H$, hot; and $D$, dry.
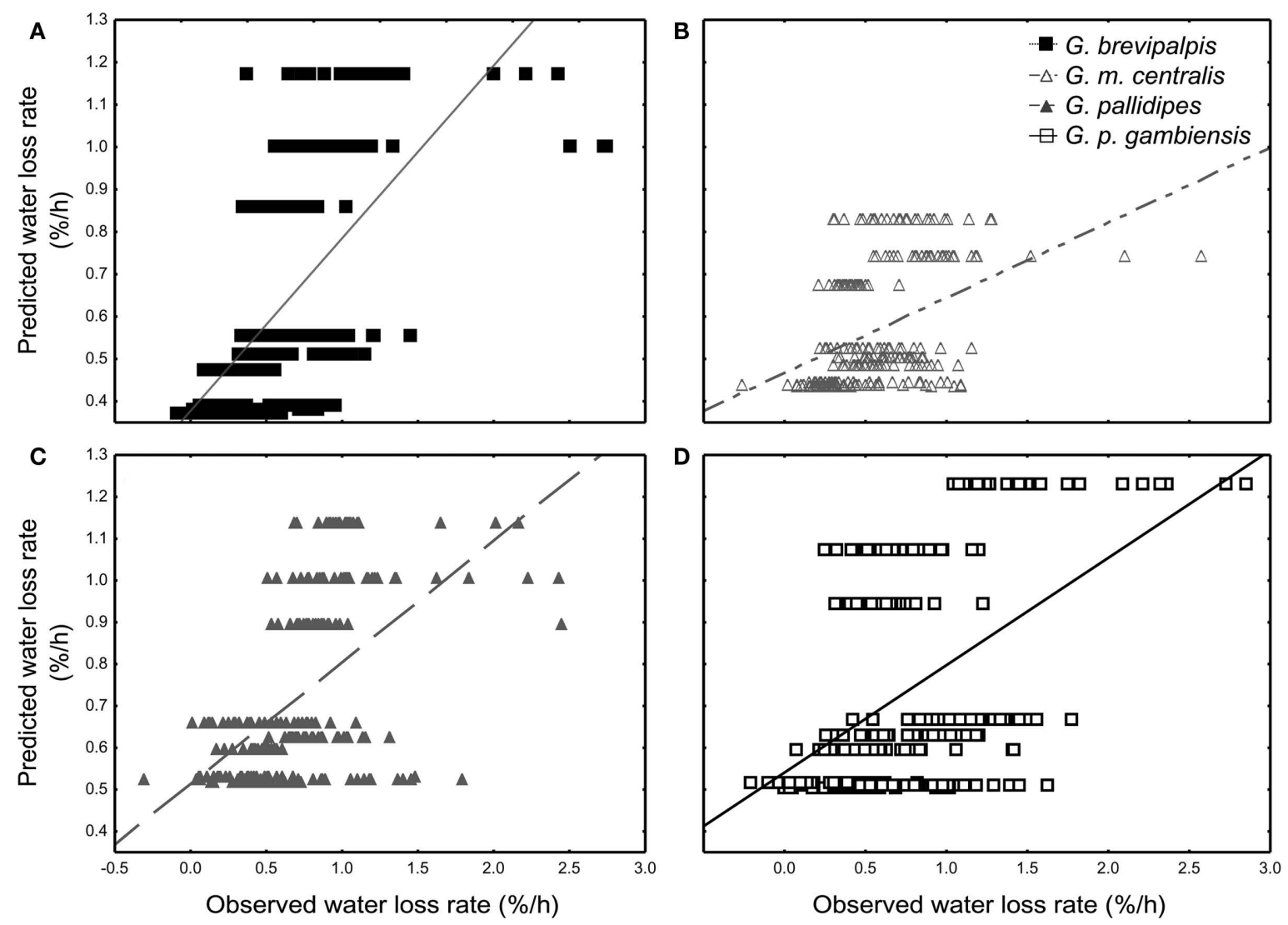

FIGURE 3 | General regression model results of the least-squares means fit for the nine distinctive treatments. The observed vs.

regression-predicted water loss rate (\% of initial body mass per hour) per

individual are plotted for (A) Glossina brevipalpis (mesic), (B) G. morsitans centralis (xeric), (C) G. pallidipes (xeric), and (D) G. palpalis gambiensis (mesic).

species from both xeric and mesic habitats. In addition, we applied a simplified mathematical model to calculate survival time of a resting fly as a function of the measured water balance traits. One of the major outcomes of this work is that the results showed that the exact conditions under which the measurements of WLR were made either amplified or reduced variation within and among species, with the greatest differences found at low relative humidity and varying temperature 
(Figure 1). One might reason that this is simply a consequence of changes in saturation deficit. However, as the subsequent analyses showed, this was not the case since WLRs were sometimes higher (and lower) than expected for a given saturation deficit (Figure 3). In sum, the results therefore suggest that both cuticular permeability, perhaps owing to temperature-dependent cuticular lipid phase changes (Gibbs, 2011), and saturation deficit together set WLR under a particular set of environmental conditions.

Water loss rates were significantly affected by measurement under different temperature and relative humidity combinations, while BWC, BLC, and mass were less strongly affected. The marked variation in WLR suggests that hot, dry environments are suboptimal for G. brevipalpis (Figure 1A). Furthermore, G. brevipalpis lost water slower than all other species in moist treatment

Table 2 | Summary of generalized linear model results [degrees of freedom (d.f.), chi-square $\left(\chi^{2}\right)$ statistic and corresponding $P$-value $\left.(P)\right]$ (normal distribution of errors and identity link function) for time to death (in $\mathrm{h}$ ) as dependent variable, initial body mass (in $\mathrm{mg}$ ) as a continuous predictor and relative humidity (in \%), temperature (in ${ }^{\circ} \mathrm{C}$ ), and species main and interaction effects (indicated with $x$ ) as model parameters.

\begin{tabular}{llll}
\hline Parameter & d.f. & $\boldsymbol{\chi 2}$ & $\boldsymbol{P}$ \\
\hline Body mass & 1 & 502.39 & $<0.0001$ \\
Species & 3 & 235.99 & $<0.0001$ \\
Humidity & 2 & 387.32 & $<0.0001$ \\
Temperature & 2 & 84.73 & $<0.0001$ \\
Species $\times$ humidity & 6 & 125.94 & $<0.0001$ \\
Species $\times$ temperature & 6 & 102.23 & $<0.0001$ \\
Humidity $\times$ temperature & 4 & 35.19 & $<0.0001$ \\
Species $\times$ humidity $\times$ temperature & 12 & 64.66 & $<0.0001$
\end{tabular}

conditions (Figure 2), which suggests the species is desiccation resistant and that there is within-ecotype variation in WLR responses. Furthermore, WLRs found here are similar to previous measurements by Terblanche et al. (2006) on G. pallidipes $\left(24^{\circ} \mathrm{C}\right.$, $0 \%$ relative humidity) and Bursell $(1957 \mathrm{a}, \mathrm{b})$ on $G$. morsitans $\left(25^{\circ} \mathrm{C}\right.$, $99 \%$ relative humidity) if compared under similar measurement conditions. These results provide support for mass-independent inter- and intra-specific variation in WLR and survival times. Therefore, water balance responses to variation in temperature and relative humidity are complex in Glossina, and this response varies within and among species, subgroups, and ecotypes in terms of both magnitude of effects and the direction of change.

Variation in the response of BWC suggests within-ecotype variation between mesic species and tighter regulation of water balance in hot, dry environments in G. p. gambiensis. There was no consistent pattern in BLC across treatments for each species, as might be expected given the short duration of the treatments and Bursell's (1959) finding that relative humidity does not have a major effect on the amount of lipid in a fly. On average, $0.8 \mathrm{mg}$ fat is metabolically oxidized in $16 \mathrm{~h}$, producing $0.86 \mathrm{mg}$ water (Bursell, 1959). Lipid consumption increases in dry air as a consequence of the orthokinetic reaction to relative humidity and is directly positively correlated with tsetse metabolism (Bursell, 1957b). Thus the BLC variation observed in these experiments is likely to be a consequence of the temperature dependence of metabolic rate (e.g., Terblanche and Chown, 2007). However, it has been argued that lipid reserves should not become depleted in dry air before death occurs by desiccation in any species of tsetse (Jack, 1939; Bursell, 1959).

Species from mesic environments did not always survive the longest in high relative humidity conditions and those from xeric environments did not always perform best at low relative humidity perhaps suggesting complex evolutionary trade-offs among currently occupied environments. However, G. p. gambiensis

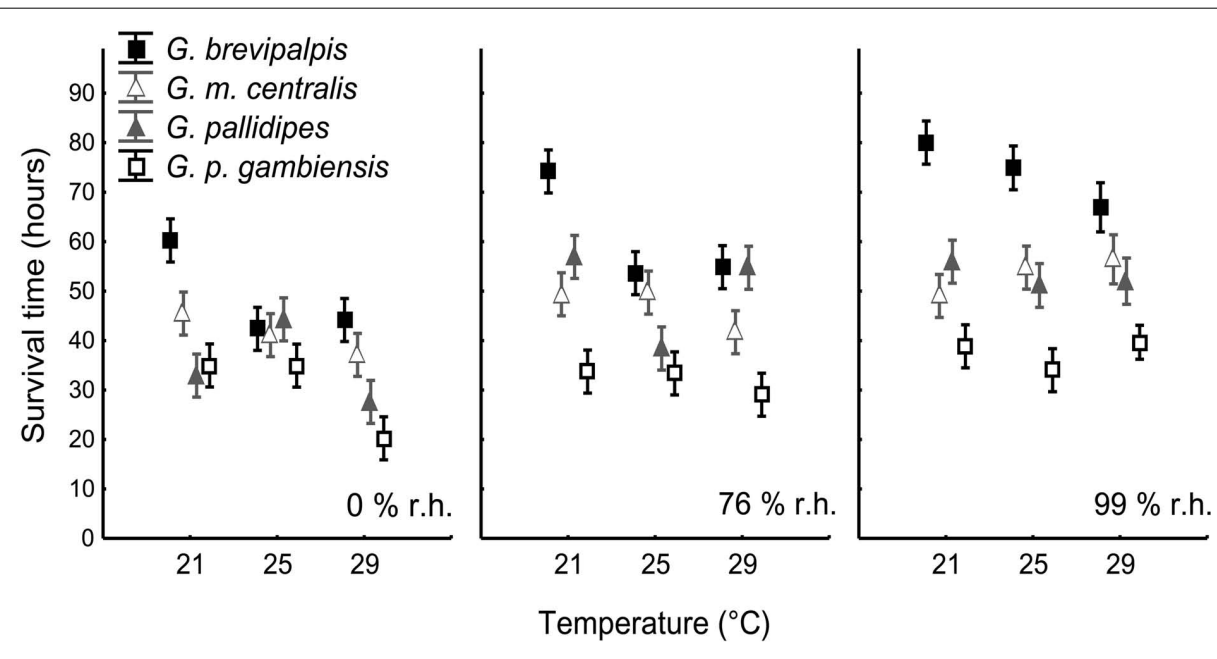

FIGURE 4 | Means ( $\pm 95 \%$ confidence intervals) for estimated survival time (in h) for Glossina brevipalpis (mesic), G. m. centralis (xeric), G. pallidipes (xeric), and G. p. gambiensis (mesic) across the range of temperature and relative humidity treatments. Mesic species are presented by squares and xeric species by triangles. Survival time is calculated as the sum of the metabolic water yield from lipids (in $\mathrm{mg}$ ), given the critical lipid mass (see Materials and Methods for details) and the initial body water content (in mg; see Materials and Methods for details), given the critical body water content of each species. This is divided by the rate of water loss (in $\mathrm{mg} \mathrm{H}_{2} \mathrm{O} / \mathrm{h}$ ) under resting conditions. All symbols are offset for clarity. 
survived all experimental conditions poorly, which is in agreement with its mesic classification. In particular, at 99\% relative humidity and at any temperature survival time was in the range of 30-40 h, a value approximately half that of G. brevipalpis. Thus, it seems that G. brevipalpis has at least partly overcome its mesic habitat restriction on the basis of its increased body size (Figures 1D and 4). Activity levels could confound our simplified estimates of survival time, especially under field conditions. However, the survival time calculations presented her consider water loss for the resting state of the adult fly for the purpose of inter-species comparison. We are therefore of the opinion that our estimates of survival time reflect the maximum likely survival time and probably overestimate survival time in the wild where a higher activity, higher WLR and, consequently, lower survival time might be expected, especially over longer durations. Thus, speciesspecific, temperature-dependent activity levels could in the future be included to make the survival time estimates more accurate.

Different effects of temperature and relative humidity within and among experimental conditions and species suggests cuticular permeability and saturation deficit are likely to be key factors in forecasting tsetse water balance responses to climate variability. Climate change is often viewed in terms of its projected effects on ambient temperature only (e.g., Deutsch et al., 2008) although it is becoming clear that such an approach may provide limited insights into realized ectotherm responses (e.g., Bonebrake and Mastrandrea, 2010; Clusella-Trullas et al., 2011). However, relative humidity is also likely to be affected, based in part on projected rainfall, fog, and cloud cover changes (e.g., Adler et al., 2008; Tebaldi and Sansó, 2009; Zhou et al., 2009). Ultimately, both relative humidity and temperature could change in different ways depending on the exact geographic location (see, e.g., Walther et al., 2002; Knapp et al., 2008; Bonebrake and Mastrandrea, 2010; Fung et al., 2011 and

\section{REFERENCES}

Addo-Bediako, A., Chown, S. L., and Gaston, K. J. (2001). Revisiting water loss in insects: a largescale view. J. Insect Physiol. 47, 1377-1388.

Adler, R. F., Gu, G., Wang, J., Huffman, G. J., Curtis, S., and Bolvin, D. (2008). Relationships between global precipitation and surface temperature on interannual and longer timescales (1979-2006). J. Geophys. Res. 113, D22104.

Bazinet, A. L., Marshall, K. E., MacMillan, H. A., Williams, C. M., and Sinclair, B. J. (2010). Rapid changes in desiccation resistance in Drosophila melanogaster are facilitated by changes in cuticular permeability. J. Insect Physiol. 56, 2006-2012.

Benoit, J. B. (2010). "Water management by dormant insects: comparisons between dehydration resistance during summer aestivation and winter diapauses," in Progress in Molecular and Subcellular Biology,

discussions in Chown et al., 2011; Clusella-Trullas et al., 2011). This study shows that due consideration of the synergistic impacts of temperature and moisture availability is important since the two potential stressors interact in fairly unexpected ways to affect measured WLRs. Moreover, given the survival time estimation results presented here, this interaction may have far-reaching implications for tsetse population dynamics, and hence, vector responses to climate change. In particular, in the four tsetse species we examined, which represented three different subgroups and two ecotypes, species WLR did not respond similarly to temperature and relative humidity variation. Perhaps the most surprising outcome is the difference in WLRs and survival time under desiccating conditions for two xeric species and two mesic species (contra Hoffmann et al., 2003), which one might have expected to respond relatively similarly, at least in the form and direction of the responses (though see also Terblanche and Kleynhans, 2009), especially after accounting for size effects. Here, we show that extrapolating water balance responses to temperature and relative humidity among species or even among ecotypes should probably be undertaken with caution. Future efforts to model tsetse species responses to climate change may therefore require species-specific information if water balance physiology is to be incorporated into mechanistic models (see, e.g., Kearney et al., 2009). This will likely increase the accuracy of predictions for the vector, thereby enabling better disease intervention planning in future.

\section{ACKNOWLEDGMENTS}

This work was financially supported by START through an African Global Change Research Grant from the US (NSF GEO-0627839) and the International Atomic Energy Agency (IAEA, contract no. 14952/R0). We are grateful for constructive comments made by Corinna Bazelet and the two referees on an earlier version of the manuscript.

Bursell, E. (1960). Loss of water by excretion and defaecation in the tsetse fly. J. Exp. Biol. 37, 689-697.

Bursell, E. (1977). Synthesis of proline by fat body of the tsetse fly (Glossina morsitans): metabolic pathways. Insect Biochem. 7, 427-434.

Bursell, E., Billing, K. C., Hargrove, J. W., McCabe, C. T., and Slack, E. (1974). Metabolism of the bloodmeal in tsetse flies (a review). Acta. Trop. 31, 297-320.

Chown, S. L. (2002). Respiratory water loss in insects. Comp. Biochem. Physiol. A Mol. Integr. Physiol. 133, 791-804.

Chown, S. L., and Nicolson, S. W. (2004). Insect Physiological Ecology. Mechanisms and Patterns. Oxford: Oxford University Press.

Chown, S. L., Sørensen, J. G., and Terblanche, J. S. (2011). Water loss in insects: an environmental change perspective. J. Insect Physiol. 57, 1070-1084.
Chown, S. L., and Terblanche, J. S. (2007). Physiological diversity in insects: ecological and evolutionary contexts. Adv. Insect Phys. 33, 50-152.

Clusella-Trullas, S., Blackburn, T. M., and Chown, S. L. (2011). Climatic predictors of temperature curve parameters in ectotherms imply complex responses to climate change. Am. Nat. 177, 738-751.

Danks, H. V. (2000). Dehydration in dormant insects. J. Insect Physiol. 46, 837-852.

Deutsch, C. A., Tewksbury, J. J., Huey, R. B., Sheldon, K. S., Ghalambor, C. K., Haak, D. C., and Martin, P. R. (2008). Impacts of climate warming on terrestrial ectotherms across latitude. Proc. Natl Acad. Sci. U.S.A. 105, 6668-6672.

Easterling, D. R., Meehl, G. A., Parmesan, C., Changnon, S. A., Karl, T. R., and Mearns, L. O. (2000). Climate extremes: observations, modeling, and impacts. Science 289, 2068-2074. 
Edney, E. B. (1967). Water balance in desert arthropods. Science 156, 1059-1066.

Edney, E. B. (1977). Water Balance in Land Arthropods. Berlin: Springer.

Fung, F., Lopez, A., and New, M. (2011). Water availability in $+2^{\circ} \mathrm{C}$ and $+4^{\circ} \mathrm{C}$ worlds. Philos. Transact. A Math. Phys. Eng. Sci. 369, 99-116.

Gefen, E., and Gibbs, A. G. (2009). Interactions between environmental stress and male mating success may enhance evolutionary divergence of stress-resistant Drosophila populations. Evolution 63, 1653-1659.

Gibbs, A. G. (2011). Thermodynamics of cuticular transpiration. J. Insect Physiol. 57, 1066-1069.

Gibbs, A. G., Chippindale, A. K., and Rose, M. R. (1997). Physiological mechanisms of evolved desiccation resistance in Drosophila melanogaster. J. Exp. Biol. 200, 1821-1832.

Gibbs, A. G., Fukuzato, F., and Matzkin, L. M. (2003). Evolution of water conservation mechanisms in Drosophila. J. Exp. Biol. 206, 1183-1192.

Gibbs, A. G., and Matzkin, L. M. (2001). Evolution of water balance in the genus Drosophila. J. Exp. Biol. 204, 2331-2338.

Hadley, N. F. (1994). Water Relations of Terrestrial Arthropods. New York: Academic Press.

Hargrove, J. W. (2001). The effect of temperature and saturation deficit on mortality in populations of male Glossina m. morsitans (Diptera: Glossinidae) in Zimbabwe and Tanzania. Bull. Ent. Res. 91, 79-86.

Hargrove, J. W. (2004). "Tsetse population dynamics," in The Trypanosomiases, eds I. Maudlin, P. H. Holmes, and M. A. Miles (Wallingford: CABI Publishing), 113-138.

Hoffmann, A. A., Hallas, R. J., Dean, J. A., and Schiffer, M. (2003). Low potential for climatic stress adaptation in a rainforest Drosophila species. Science 301, 100-102.

Hoffmann, A. A., and Harshman, L. G. (1999). Desiccation and starvation resistance in Drosophila: patterns of variation at the species, population and intrapopulation levels. Heredity $83,637-643$.

Jack, R. W. (1939). Studies in the physiology and behaviour of Glossina morsitans Westw.Memoirs of the Department of Agriculture, Southern Rhodesia, no. 1.

Jurenka, R., Terblanche, J. S., Klok, J., Chown, S. L., and Krafsur, E. S. (2007). Cuticular lipid mass and desiccation rates in
Glossina pallidipes: interpopulation variation. Physiol. Entomol. 32, 287-293.

Kearney, M., Porter, W. P., Williams, C., Ritchie, S., and Hoffmann, A. A. (2009). Integrating biophysical models and evolutionary theory to predict climatic impacts on species' ranges: the dengue mosquito Aedes aegypti in Australia. Funct. Ecol. 23, 528-538.

Kessler, S., and Guerin, P. M. (2008). Responses of Anopheles gambiae, Anopheles stephani, Aedesa egypti, and Culex pipiens mosquitoes (Diptera: Culicidae) to cool and humid refugium conditions. $J$. Vector Ecol. 33, 145-149.

Kleynhans, E., and Terblanche, J. S. (2009). The evolution of water balance in Glossina (Diptera: Glossinidae): correlations with climate. Biol. Lett. 5, 93-96.

Knapp, A. K., Beier, C., Briske, D. D., Classen, A. T., Luo, Y., Reichstein, M., Smith, M. D., Smith, S. D., Bell, J. E., Fay, P. A., Heisler, J. L., Leavitt, S. W., Sherry, R., Smith, B., and Weng, E. (2008). Consequences of more extreme precipitation regimes for terrestrial ecosystems. Bioscience $58,811-821$.

Le Lagadec, M. D., Chown, S. L., and Scholtz, C. H. (1998). Desiccation resistance and water balance in Southern African Keratin beetles (Coleoptera, Trogidae): the influence of body size and habitat. J. Comp. Physiol. B Biochem. Syst. Environ. Physiol. 168, 112-122.

Leak, S. G. A. (1999). Tsetse Biology and Ecology. Their Role in the Epidemiology and Control of Trypanosomosis. New York: CABI Publishing.

Lopez-Martinez, G., Benoit, J. B., Rinehart, J. P., Elnitsky, M. A., Lee, R. E. Jr., and Denlinger, D. L. (2009). Dehydration, rehydration and overhydration alter patterns of gene expression in the Antarctic midge, Belgica antarctica. J. Comp. Physiol. B 179, 481-491.

Marron, M. T., Markow, T. A., Kain, K. J., and Gibbs, A. G. (2003). Effects of starvation and desiccation on energy metabolism in desert and mesic Drosophila. J. Insect Physiol. 49, 261-270.

Matzkin, L. M., Watts, T. D., and Markow, T. A. (2009). Evolution of stress resistance in Drosophila: interspecific variation in tolerance to desiccation and starvation. Funct. Ecol. $23,521-527$.

Norden, D. A., and Paterson, D. J. (1969). Carbohydrate metabolism in flight muscle of the tsetse fly (Glossina) and the blowfly
(Sarcophaga). Comp. Biochem. Physiol. 31, 819-827.

Rogers, D. J., and Randolph, S. E. (1986). Distribution and abundance of tsetse flies (Glossina spp.). J. Anim. Ecol. 55, 1007-1025.

Rogers, D. J., and Robinson, T. P. (2004). "Tsetse distribution," in The Trypanosomiases, eds I. Maudlin, P. H. Holmes, and M. A. Miles (Wallingford: CABI Publishing), 139-180.

Simard, F., Ayala, D., Kamdem, G. C. Pombi, M., Etouna, J., Ose, K., Fotsing, J. M., Fontenille, D., Besansky, N. J., and Constantini, C. (2009). Ecological niche partitioning between Anopheles gambiae molecular forms in Cameroon: the ecological side of speciation. BMC Ecol. 9, 17. doi:10.1186/1472-6785-9-17

Tebaldi, C., and Sansó, B. (2009). Joint projections of temperature and precipitation change from multiple climate models: a hierarchical Bayesian approach. J. R. Stat. Soc. Ser. A Stat. Soc. 172, 83-106.

Terblanche, J. S., and Chown, S. L. (2007). The effects of temperature, body mass and feeding on metabolic rate in the tsetse fly Glossina morsitans centralis. Physiol. Entomol. 32, 175-180.

Terblanche, J. S., Clusella-Trullas, S., and Chown, S. L. (2010). Phenotypic plasticity of gas exchange pattern and water loss in Scarabaeus spretus (Coleoptera: Scarabaeidae): deconstructing the basis for metabolic rate variation. J. Exp. Biol. 213 , 2940-2949.

Terblanche, J. S., Clusella-Trullas, S., Deere, J. A., and Chown, S. L. (2008). Thermal tolerance in a south-east African population of the tsetse fly Glossina pallidipes (Diptera, Glossinidae): implications for forecasting climate change impacts. $J$. Insect Physiol. 54, 114-127.

Terblanche, J. S., and Kleynhans, E. (2009). Phenotypic plasticity of desiccation resistance in Glossina puparia: are there ecotype constraints on acclimation responses? J. Evol. Biol. 22, 1636-1648.

Terblanche, J. S., Klok, C. J., and Chown, S. L. (2004). Metabolic rate variation in Glossina pallidipes (Diptera: Glossinidae): gender, ageing and repeatability. J. Insect Physiol. 50, 419-428.

Terblanche, J. S., Klok, C. J., and Chown, S. L. (2005). Temperature dependence of metabolic rate in Glossina morsitans morsitans (Diptera, Glossinidae) does not vary with gender, age, feeding, pregnancy or acclimation. J. Insect Physiol. 51, 861-870.
Terblanche, J. S., Klok, C. J., Krafsur, E. S., and Chown, S. L. (2006). Phenotypic plasticity and geographic variation in thermal tolerance and water loss of the tsetse Glossina pallidipes (Diptera: Glossinidae): implications for distribution modelling. Am. J. Trop. Med. Hyg. 74, 786-794.

Walther, G. R., Post, E., Convey, P., Menzel, A., Parmesan, C., Beebee, T. J. C. Fromentin, J. M., Hoegh-Guldberg, O., and Bairlein, F. (2002). Ecological responses to recent climate change. Nature 416, 389-395.

Woods, H. A., and Harrison, J. F. (2001). The beneficial acclimation hypothesis versus acclimation of specific traits: physiological change in waterstressed Manduca sexta caterpillars. Physiol. Biochem. Zool. 74, 32-44.

Woods, H. A., and Smith, J. N. (2010). Universal model for water costs of gas exchange by animals and plants. Proc. Natl Acad. Sci. U.S.A. 107, 8469-8474

Yoder, J. A., Benoit, J. B., LaCagnin, M. J., and Hobbs, H. H. III. (2011) Increased cave dwelling reduces the ability of cave crickets to resist dehydration. J. Comp. Physiol. B 181, 595-601.

Zhou, L., Dai, A., Cai, Y., Vose, R. S., Zou, C., Tian, Y., and Chen, H. (2009). Spatial dependence of diurnal temperature range trends on precipitation from 1950 to 2004. Clim. Dyn. 32, 429-440.

Conflict of Interest Statement: The authors declare that the research was conducted in the absence of any commercial or financial relationships that could be construed as a potential conflict of interest.

Received: 10 August 2011; paper pending published: 13 September 2011; accepted: 04 October 2011; published online: 25 October 2011.

Citation: Kleynhans E and Terblanche JS (2011) Complex interactions between temperature and relative humidity on water balance of adult tsetse (Glossinidae, Diptera): implications for climate change. Front. Physio. 2:74. doi: 10.3389/fphys.2011.00074

This article was submitted to Frontiers in Invertebrate Physiology, a specialty of Frontiers in Physiology.

Copyright (๑) 2011 Kleynhans and Terblanche. This is an open-access article subject to a non-exclusive license between the authors and Frontiers Media $S A$, which permits use, distribution and reproduction in other forums, provided the original authors and source are credited and other Frontiers conditions are complied with. 